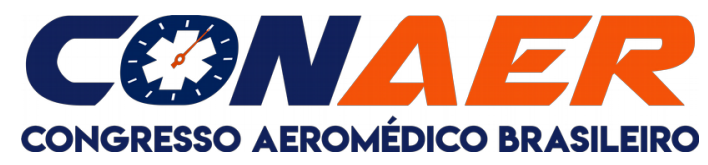

\title{
INTRODUÇÃO EM ENFERMAGEM AEROESPACIAL PARA RESIDENTES DE ENFERMAGEM EM URGÊNCIA E TRAUMA: RELATO DE EXPERIÊNCIA
}

\author{
Herberth Jessie MARTINS'; jade Fonseca Ottoni de CARVALHO²; Deiversandson \\ Arruda RAMOS ${ }^{3}$; Vanessa Rocha da SILVA ${ }^{4}$
}

\section{RESUMO}

O transporte aéreo de pacientes graves exige a presença do enfermeiro, contudo essa discussão não está na grade curricular do Programa de Residência em Enfermagem em Urgência e Trauma da Secretaria de Estado de Saúde do Distrito Federal (SES-DF). Justificativa: a realização do treinamento está na importância do estudo do tema para os Residentes do Curso de Enfermagem em Urgência e Trauma, e a necessidade de conscientizá-los sobre a atuação do serviço de atendimento pré-hospitalar aéreo como parte da rede de assistência em saúde do Distrito Federal. Objetivos: apresentar aos Residentes o trabalho desempenhado pelo Grupamento de Aviação Operacional (GAVOP) do Corpo de Bombeiros do Distrito Federal, realizar treinamento teórico e prático em solo sobre os aspectos operacionais das atividades do enfermeiro e discutir sobre tecnologias empregadas na assistência em saúde em um serviço de atendimento pré-hospitalar aéreo. Método: a discussão de conteúdo teórico, por meio de metodologia ativa, e treinamento prático de atividades operacionais desempenhadas por enfermeiros durante assistência em saúde no transporte com helicópteros. Resultado: programação de outros treinamentos similares envolvendo novas turmas de Residência em Enfermagem. A atividade em questão envolveu a participação ativa de enfermeiros de um serviço de resgate aéreo como instrutores em um treinamento que utilizou um processo de aprendizagem significativa na formação do Programa de Residência em Enfermagem em Urgência e Trauma da Secretaria de Estado de Saúde do Distrito Federal.

Palavras-chave: resgate aéreo, capacitação, educação em enfermagem.

\section{INTRODUÇÃO}

A qualificação para a atuação do enfermeiro em serviços aéreos de transporte de pacientes é ainda nova no Brasil e tem crescido bastante nos últimos anos. Contudo, os aspectos operacionais desses serviços, já existentes há décadas, não são amplamente conhecidos pelos profissionais de enfermagem em algumas regiões do país. Nesse contexto foi realizado um treinamento para Residentes de Enfermagem em Urgência e Trauma, para que estes novos profissionais entendam a dinâmica de um serviço aéreo de atendimento a emergências, bem como as tecnologias que podem ser empregadas na assistência em saúde aos enfermos graves que se beneficiam de transporte aéreo.

\footnotetext{
1 Enfermeiro, Pós-graduação em Enfermagem Aeroespacial, SAMU-DF, herberthmartins@yahoo.com.br

2 Enfermeira, Mestre em Enfermagem, Centro Universitário UDF, jadeottoni@gmail.com

3 Enfermeiro, Pós-graduação em Enfermagem Aeroespacial, SAMU-DF, deiversan@gmail.com

4 Enfermeira, Pós-graduação em Enfermagem Aeroespacial, SAMU-DF, vanessarocha_00@yahoo.com.br
} 


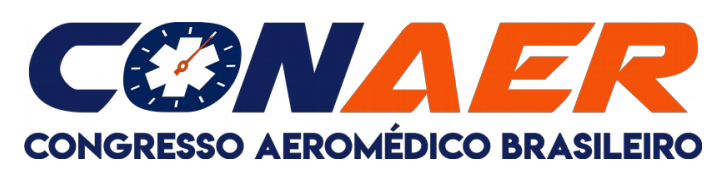

\section{METODOLOGIA}

Trata-se de uma pesquisa descritiva, pois segundo Gerhardt e Silveira (2009), nesse método são descritos fatos e fenômenos de determinada realidade.

O método empregado no treinamento foi dividido em três momentos, sendo o primeiro dedicado à exposição de assuntos básicos da Fisiologia do voo, ministrados por enfermeiros do serviço. O segundo momento foi a discussão de artigos científicos conduzida pelos Residentes de enfermagem. O terceiro momento foram atividades práticas de embarque e desembarque de pacientes em helicópteros, manuseio de equipamentos embarcados e segurança do paciente e da equipe profissional.

O treinamento prático foi realizado com as aeronaves em solo e sem 0 acionamento dos rotores por questões de segurança. Ao final do treinamento foi realizado um debriefing para que os Residentes fizessem uma exposição sobre a adequação do método empregado e a relevância do treinamento na formação do grupo.

\section{RESULTADOS E DISCUSSÕES}

A primeira etapa do treinamento foi uma apresentação expositiva de três assuntos relevantes para a compreensão da especificidade da assistência em saúde ao paciente gravemente enfermo aerotransportado. Os assuntos foram: disbarismos, efeitos da aceleração na fisiologia humana e segurança do paciente durante as fases do voo.

$\mathrm{Na}$ segunda etapa do treinamento teórico, os residentes apresentaram o estado da arte acerca do uso de hemoderivados no atendimento pré-hospitalar, o uso da ecografia no atendimento pré-hospitalar e a segurança do paciente em ambiente aeroespacial. Todas as discussões envolvidas nessa etapa foram conduzidas pelos Residentes em Enfermagem, para que através de um método ativo, houvesse um aprendizado significativo, pois segundo Moreira (2013), a aprendizagem significativa se caracteriza pela interação entre conhecimentos prévios e conhecimentos novos.

Ainda com a intenção de proporcionar um aprendizado significativo, foi realizada a terceira etapa do treinamento. Nessa etapa foram realizadas atividades práticas em heliponto e no interior de dois helicópteros - AS350 B2 e EC 135 T2. 
O resultado desse treinamento foi a aquisição de conhecimentos, por parte dos Residentes em Enfermagem, sobre a dinâmica de trabalho de um serviço aéreo de resgate e transporte de pacientes e a atuação do enfermeiro em todo o processo assistencial e de gestão. A enfermagem aeroespacial é um campo profissional muito específico e normalmente os conteúdos de formação tradicional não apresentam essa modalidade de atuação do enfermeiro, conforme apresentado na pesquisa de Passos, Toledo e Duran (2011).

Outro apontamento importante foi realizado pelos enfermeiros do serviço, que participaram do treinamento como instrutores. Estes relataram o quanto é importante a troca de experiências entre gerações diferentes de profissionais e que essa poderia ser uma forma de construção de um processo de educação permanente.

A educação permanente parte do pressuposto que a aprendizagem deve ser significativa. Os processos de capacitação do pessoal da saúde devem ser estruturados a partir da problematização do processo de trabalho (OLIVEIRA, 2011).

Nesse treinamento os participantes tiveram a oportunidade de conhecer assuntos importantes para a assistência em atendimento pré-hospitalar, como o uso de hemoderivados nas pesquisas de Heschl et al (2017), Brown et al (2015) e Avest et al (2019) e o uso de ultrassonografia, principalmente para vítimas de trauma como pode ser visto em Mason (2018).

\section{CONSIDERAÇÕES FINAIS}

Devido a uma fragilidade na grade curricular de alguns cursos de graduação e até mesmo de pós-graduação, os serviços aéreos que fazem parte da rede de assistência em saúde do Sistema Único de Saúde, não são devidamente apresentados como um serviço especializado e pertencente às redes públicas de saúde.

Os profissionais com menor tempo de formação, principalmente aqueles que são provenientes de cursos mais robustos como aqueles em formato de Residência, têm um enorme potencial de contribuição para atuação atualizada e mais crítica daqueles profissionais que estão em suas áreas de trabalho há muito tempo, e que por diversos motivos podem se encontrar carentes de atualização, principalmente quando o assunto são as novas tecnologias de assistência em saúde. 


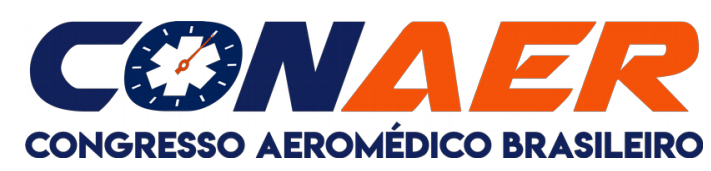

\section{REFERÊNCIAS}

AVEST et al. Out-of-hospital cardíaca arrest following trauma: what does a helicopter emergency medical service offer? Resuscitation, v. 135, p. 73-79, dez. 2018. Disponível em:<https://www.ncbi.nlm.nih.gov/m/pubmed/30597132/>. Acesso em: 25 maio 2019.

BROWN, J.B. et al. Pre-trauma center red blood cell transfusion is associated with improved early outcomes in air medical trauma patients. Journal of the American College of Surgeons, v. 220, n. 5, p. 797- 808, jan. 2015. Disponível em: <https://www.ncbi.nlm.nih.gov/pubmed/25840537>. Acesso em: 20 maio 2019.

GERHARDT, T. E.; SILVEIRA, D. T. Métodos de pesquisa. Universidade Federal do Rio Grande do Sul. Porto Alegre: Ed da UFRS, 2009. Disponível em: < http://www.ufrgs.br/cursopgdr/downloadsSerie/derad005.pdf>. Acesso em: 2 junho 2019.

HESCHL, S. et al. Prehospital transfusion of red cell concentrates in a paramedicstaffed helicopter emergency medical service. Emergency Medicine Australasia, v. 30 , n. 2, p. 236-241, Apr. 2017. Disponível em: <https://onlinelibrary.wiley.com/doi/pdf/10.1111/1742-6723.12910>. Acesso em: 20 maio 2019.

MASON, R. et al. Teaching flight nurses ultrasonographic evaluation of esophageal intubation and pneumothorax. Air Medical Journal, v. 38, n. 3, p. 195-197, jun. 2019.

<https://www.sciencedirect.com/science/article/pii/S1067991X1830155X>. Acesso em: 18 jul. 2019.

MOREIRA, M. A. Aprendizagem significativa, organizadores prévios, mapas conceituais, diagramas $\mathrm{V}$ e unidades de ensino potencialmente significativas. Tese de doutorado. Instituto de Física. Universidade Federal do Rio Grande do Sul. Porto Alegre. 2013. Disponível em: <https://www.if.ufrgs.br/ moreira/apsigmapasport.pdf>. Acesso em: 15 maio 2019.

OLIVEIRA, F. M. C. S. N. et al. Educação permanente e qualidade da assistência à saúde: aprendizagem significativa no trabalho da enfermagem. Aquichan, v. 11, n. 1, p. 48-65, abril 2011. Disponível em: <http://www.scielo.org.co/pdf/aqui/v11n1/v11n1a05.pdf>. Acesso em: 12 maio 2019.

PASSOS, I. P. B. D.; TOLEDO, V. P.; DURAN, E. C. M. Transporte aéreo de pacientes: análise do conhecimento científico. Revista Brasileira de Enfermagem, v. 64, n. 6, p. 1127-1131, dez. 2011. Disponível em: <http://www.scielo.br/pdf/reben/v64n6/v64n6a21.pdf>. Acesso em: 10 maio 2019. 